\title{
James G. Speight: Handbook of Petroleum Refining
}

\author{
Edward R. Adlard ${ }^{1}$
}

(C) Springer-Verlag Berlin Heidelberg 2017

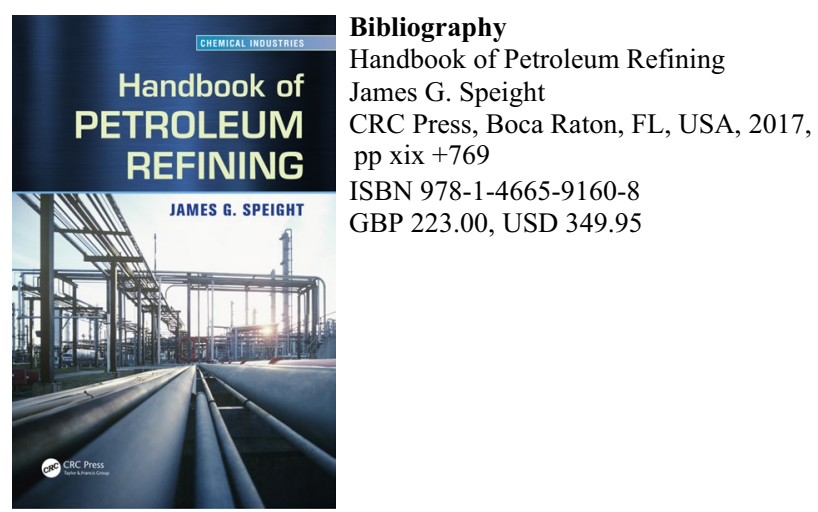

CRC Press seems to specialize in "Handbooks" on a variety of subjects and one of my most valued possession when I was actively engaged in research was a copy of the Handbook of Chemistry and Physics (or the "Rubber Handbook" as it was colloquially known) which contained everything from the melting point of sodium hydroxide to the Greek symbol for " $\mathrm{z}$ ". The only misleading thing about these books is the name "handbook" since most of them weigh in at well over a kilogram (the current volume is over $1.6 \mathrm{~kg}$ ) and a more appropriate name would be "The Encyclopaedia of..." (in this case the Encyclopaedia of Petroleum Refining") since it covers everything the reader would wish to know about the subject.

Edward R. Adlard

e.adlard77@btinternet.com

1 Burton, South Wirral, UK
As a young graduate in the petroleum industry, I was sent on a course on which each attendee was presented with $50 \mathrm{~L}$ of crude oil which was then subjected to as many of the operations that were used in the refinery as were practical in the laboratory- atmospheric distillation, vacuum distillation, etc. These fractions were then subjected to many of the routine tests such as vapour pressure, distillation range and oxidation stability. The present book would have been an ideal accompaniment if it been available at that time. At nearly 800 pages in length, there is little omitted that one would need to know about petroleum refining, from crude oil itself through LNG to bitumen.

I have been critical of some the author's publications in the past, but this one I can totally praise and recommend to anyone wishing to know more about the oil industry. The general public is apt to associate the industry with adverse comments on global warming and air pollution but it should be born in mind that modern agriculture would not be able to supply the world's food requirements without the aid of machinery run on diesel fuel. It may be that future energy sources will replace oil-derived fuels in due course, but currently this is a long way off. 